\title{
Fibers in the Anastomotic Branches Connecting the Bilateral Pelvic Rectal Plexuses of the Dog
}

\author{
Hiroyuki FukUda and Kiyoko FuKaI \\ Department of Physiology, Kawasaki Medical School, \\ Kurashiki, Okayama, 701-01 Japan
}

\begin{abstract}
Summary Types of fibers in the anastomotic branches connecting the bilateral pelvic plexuses were electrophysiologically defined in dogs. The branches consist of $\mathrm{A} \delta$ and $\mathrm{C}$ afferent fibers, and parasympathetic preganglionic $\mathrm{B}$ and post-ganglionic $\mathrm{C}$ fibers.
\end{abstract}

Key words: pelvic nerve, rectum, parasympathetic fibers.

In the dog, the bilateral pelvic rectal plexuses are connected by two or three anastomotic branches which traverse the ventral surface of the rectum (MizerEs, 1955). However, we have not been able to find information concerning the types of fibers used in the branches. As a result, our purpose is to elucidate the types of fibers in the branches.

Experiments were performed on 12 dogs anesthetized with intravenous $\alpha$ chloralose $(100 \mathrm{mg} / \mathrm{kg})$. The dogs were paralyzed with intravenous gallamine triethiodide $(1 \mathrm{mg} / \mathrm{kg})$, then artificially ventilated through a tracheal cannula. The roots of the sacral cord and the pelvic nerves were exposed, as described elsewhere (FuKaI and FuKUdA, 1985). The rectal strands, which branch from the pelvic rectal plexus and invade the rectal wall were exposed bilaterally together with the anastomotic branches, by an excision of the bladder and the proximal urethra. Urine was drained by cannulation of both ureters. The lumbar colonic nerve, the right pelvic nerve and the hypogastric nerves were severed in all cases. Responses of the anastomotic branches and rectal strands to stimulation of the roots of the sacral nerves were averaged 100 times with an averager. Bipolar platinum wire electrodes were used for stimulation and recordings.

Hexamethonium bromide (C6), $0.2 \%(w / v)$ in Tyrode solution, was applied to the pelvic ganglia via a polyethylene tube inserted centripetally into the internal pudendal artery (Fig. 1).

Responses of three anastomotic branches were simultaneously averaged during stimulation of peripheral cut ends of ventral roots (Fig. 1B, C, and E) or dorsal

Received for publication April 24, 1985 


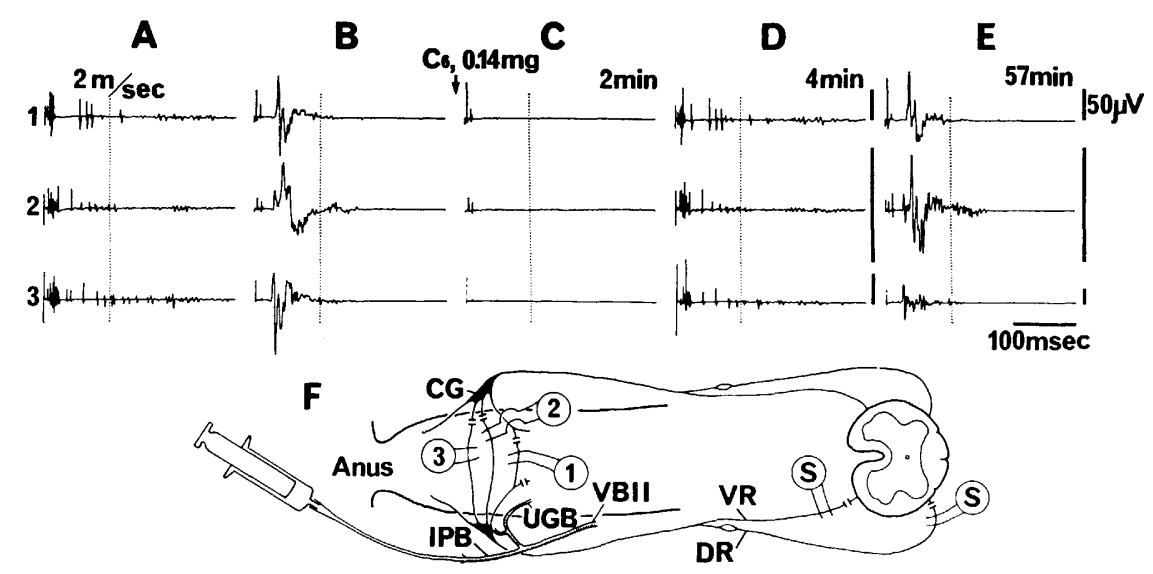

Fig. 1. Responses of the anastomotic branches to stimulation of ventral and dorsal roots of the sacral nerves. Traces 1, 2, and 3 were recorded by three pairs of electrodes (1, 2 , and 3 in F) from three anastomotic branches. A and D: responses to stimulation of the sacral dorsal roots (DR), with pulses of $0.5 \mathrm{msec}$ duration, $0.5 \mathrm{~Hz}$, and $20 \mathrm{~V}$. B, $\mathrm{C}$, and $\mathrm{E}$ : responses to stimulation of the sacral ventral roots (VR), with pulses of 0.5 msec duration, $0.5 \mathrm{~Hz}$, and $10 \mathrm{~V}$. Vertical dotted lines in A-E show the latency expected for the response of the fiber having the conduction velocity of $2 \mathrm{~m} / \mathrm{sec}$. Between B and C, C6 $(0.14 \mathrm{mg})$ was injected into the internal pudendal artery (IPB) on the stimulating side. Time that elapsed after the injection is shown above the records in $\mathrm{C}, \mathrm{D}$, and E. F: experimental arrangement. S, stimulating electrode; VBII, visceral branch of the internal iliac artery; UGB, urogenital artery. The same abbreviations are used in Fig. 2.

roots (Fig. 1A and D) of the three sacral nerves. In the response to ventral root stimulation, small B fiber peaks appeared after a short latency, followed by larger $\mathrm{C}$ fiber peaks. Most of the $\mathrm{C}$ fiber peaks appeared with the latency shorter than that expected for the response of the fiber having the conduction velocity of 2 $\mathrm{m} / \mathrm{sec}$. This result shows that the response is evoked through the intermediary of the preganglionic B fibers; accordingly the $\mathrm{C}$ fiber peaks disappeared completely after C6 was applied intra-arterially to the pelvic plexus of the stimulating side. However, the B fiber peaks responding to the same stimulation, and peaks of A $\delta$ and $\mathrm{C}$ fibers responding to dorsal root stimulation, were not affected by $\mathrm{C} 6$ (Fig. $1 \mathrm{C}$ and $\mathrm{D})$. The efferent $\mathrm{C}$ fiber peaks recovered about $1 \mathrm{hr}$ after the injection of C6.

These results show that the anastomotic branches, consist of parasympathetic preganglionic $\mathrm{B}$ fibers and post-ganglionic $\mathrm{C}$ fibers, and $\mathrm{A} \delta$ and $\mathrm{C}$ afferent fibers.

Fiber types of twelve anastomotic branches of seven dogs were examined in similar experiments. Six of the twelve branches consisted of all four types of fibers. One branch had pre- and post-ganglionic efferent fibers and A $\delta$ afferent fibers. Two branches contained pre- and post-ganglionic fibers. The remaining three 


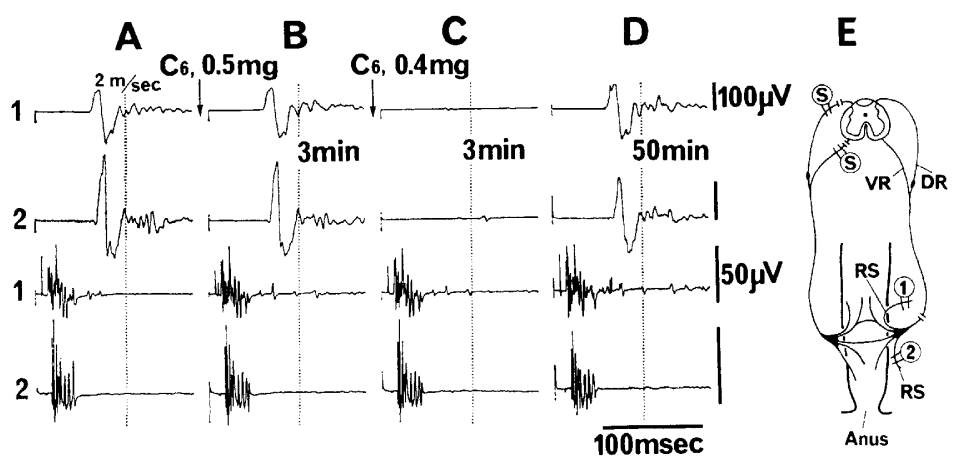

Fig. 2. Responses of the rectal strands to stimulation of dorsal and ventral roots of the contralateral sacral nerves. Arrangement of this experiment is shown in E. Traces 1 and 2 were simultaneously recorded by electrodes 1 and 2 from two separate rectal strands. The upper two traces show responses to stimulation of the ventral roots $(0.5 \mathrm{msec}, 0.5 \mathrm{~Hz}, 10 \mathrm{~V})$. The lower two traces show responses to stimulation of the dorsal roots $(0.5 \mathrm{msec}, 0.5 \mathrm{~Hz}, 20 \mathrm{~V})$. Vertical dotted lines in A-D show the latency expected for the response of the fiber having the conduction velocity of $2 \mathrm{~m} / \mathrm{sec}$. Between $A$ and $B, C 6(0.5 \mathrm{mg})$ was injected into the internal pudendal artery of the recording side. Responses of B were obtained about 3 min after the injection of C6. Between B and $\mathrm{C}$, a second dose of $\mathrm{C} 6(0.5 \mathrm{mg})$ was injected into the artery of the stimulating side. Responses of $\mathrm{C}$ and $\mathrm{D}$ were obtained about 3 and $50 \mathrm{~min}$ after the second injection of C6, respectively.

branches had, respectively, post-ganglionic $\mathrm{C}$ fibers and $\mathrm{A} \delta$ afferent fibers, $\mathrm{A} \delta$ and $\mathrm{C}$ afferent fibers, and only post-ganglionic $\mathrm{C}$ fibers.

Figure 2 shows the responses of two rectal strands to stimulation of the contralateral sacral roots. Only $\mathrm{C}$ fiber peaks were obvious in the responses to stimulation of the ventral roots. Similar responses were confirmed in ten rectal strands of five dogs. No preganglionic B fiber peak was observed in any response of these strands to the ventral root stimulation. These results show that preganglionic B fibers traveled through the pelvic nerve of one side and that the anastomotic branches synapse with the post-ganglionic cells in the pelvic rectal plexus of the other side.

No clear change in the responses to ventral root stimulation was brought about by applying $\mathrm{C} 6$ to the ganglia in the pelvic plexus of the recording side (Fig. 2B). The C fiber peaks, however, disappeared almost completely when C6 was applied to the ganglia of the stimulating side (Fig. 2C). Both effects of C6 were observed when the order of its application was reversed. After the application of $\mathrm{C} 6$, the $\mathrm{A} \delta$ and $\mathrm{C}$ fiber peaks were also observed in their response to dorsal root stimulation. Similar effects of $\mathrm{C} 6$ were observed in all ten rectal strands.

Now these results show that the post-ganglionic fibers, which travel from pelvic ganglia of one side to the other side, through the anastomotic branches, 
do not synapse with any ganglion cell in the contralateral ganglia.

These observations are consistent with the two findings as follows: 1) many non-myelinated and some myelinated fibers are observed in rectal strands of the pelvic nerve, which had been cut together with the hypogastric nerve and had undergone degeneration (FUKAI and FUKUDA, 1985); 2) ascending nerves of the colon, which arise from the pelvic nerves and pass up the colon between the longitudinal and circular muscle layers (STACH, 1971; CHRISTENSEN et al., 1984), are composed of $\mathrm{A} \delta$ and $\mathrm{C}$ afferent fibers and parasympathetic post-ganglionic $\mathrm{C}$ fibers coming from the bilateral pelvic nerves (FUKAI and FUKUDA, 1984).

\section{REFERENCES}

Christensen, J., Stiles, M. J., Rick, G. A., and Sutherland, J. (1984) Comparative anatomy of the myenteric plexus of the distal colon in eight mammals. Gastroenterology, 86: 706713.

Fukal, K. and FukUda, H. (1984) The intramural pelvic nerves in the colon of dogs. $J$. Physiol. (Lond.), 354: 89-98.

FukaI, K. and FUKUdA, H. (1985) Three serial neurons in the innervation of the colon by the sacral parasympathetic nerve of the dog. J. Physiol. (Lond.), 362: 69-78.

Mizeres, N. J. (1955) The anatomy of the autonomic nervous system in the dog. Am. J. Anat., 96: 285-318.

StACH, W. (1971) Über die in der Dickdarmwand aszendierenden Nerven des Plexus pelvinus und die Granze der vagalen und sakralparasympathischen Innervation. Z. Mikrsk. Anat. Forsch., 84: 65-90. 